\title{
SEASONAL VARIATION OF INTESTINAL PARASITOSIS IN KISHANGANJ DISTRICT, BIHAR
}

\author{
Bhattacharya Pramukh¹, Bhattacharya Rituparna², Paul Uttam Kumar³, Bandyopadhyay Arup ${ }^{4}$ \\ ${ }^{1}$ Associate Professor, Department of Microbiology, MGM Medical College, Kishanganj. \\ ${ }^{2}$ Assistant Professor, Department of Microbiology, MGM Medical College, Kishanganj. \\ ${ }^{3}$ Professor, Department of Medicine, MGM Medical College, Kishanganj. \\ ${ }^{4}$ Professor, Department of Physiology, MGM Medical College, Kishanganj.
}

ABSTRACT

\section{BACKGROUND}

Seasonal variations in temperature, rainfall and resource availability are ubiquitous and can exert strong pressures on population dynamics. Several past studies, including a study on humans from the United States and a few others using animal subjects have revealed the burden of parasitic infections to rise during the monsoon months (July to October), showing the lowest load during winter. An attempt to assess the influence of seasonal variations on the prevalence of IPI, a retrospective study was done for a period of 36 months in our Tertiary Care Hospital in the eastern part of Bihar.

\section{MATERIALS AND METHODS}

The present study is a retrospective study undertaken in a rural medical college of Bihar, India. Patients of all ages who reported with gastrointestinal symptoms during the period of Jan. 2014 to Dec. 2016 were included in the study. A total number of 5638 patients of both sexes were found to fulfil the criteria of inclusion. Routine macroscopic examinations of stool were carried as per standard guidelines for presence of adult worms, scolices and proglottids. For microscopic examinations, saline wet mount and Lugol's iodine wet mount were prepared as per standard protocol.

\section{RESULTS}

Our study was done retrospectively on 5638 stool specimens obtained from patients who were referred from outpatient departments (OPD). It was found that out of 5638 stool specimens examined, 1489 were sent during the monsoon itself out of which 698 (46.88\%) specimens were positive for parasites. In other words, out of total 2672 parasite-positive specimens in a total span of three years, the monsoon brunt was $26.12 \%$, compared to the winter counterpart which was 251 , i.e. only $9.39 \%$. After rainy season, the next parasitic cases were found in the order of: summer (601, i.e. 22.47\%), autumn (417, i.e. 15.6\%), dewy season (389, i.e. $14.56 \%)$, spring (316, i.e. $11.83 \%$ ) and lastly winter as already mentioned (251, i.e. 9.39\%). It has to be noted here that rainfall does not necessarily occur solely during rainy season, but also in other seasons, notably in summer and autumn. Our study tallies well with other similar studies.

\section{CONCLUSION}

Our studies reveal that the situation of intestinal parasitosis is maximum in summer and rainy seasons and minimum in dry, winter months. Periodic preventive anti-helminthic treatment should be instituted keeping in view with these findings.

\section{KEYWORDS}

Seasonal Variation, Intestinal Parasitosis, Bihar.

HOW TO CITE THIS ARTICLE: Pramukh B, Rituparna B, Kumar PU, et al. Seasonal variation of intestinal parasitosis in Kishanganj district, Bihar. J. Evolution Med. Dent. Sci. 2017;6(41):3227-3230, DOI: 10.14260/Jemds/2017/699

\section{BACKGROUND}

Intestinal parasitic infections (IPI) are endemic worldwide, and it represents a large and serious medical health problem in the developing countries, with high prevalence rate in many regions. It is estimated that 3.5 billion people are affected, and 450 million are ill as a result of these infections, the majority being children.[1] The distribution and prevalence of various intestinal parasite species depend on social, geographical and economic conditions, as well as

Financial or Other, Competing Interest: None.

Submission 03-04-2017, Peer Review 09-05-2017,

Acceptance 15-05-2017, Published 22-05-2017.

Corresponding Author:

Bandyopadhyay Arup,

Professor,

Department of Physiology,

MGM Medical College,

Kishanganj-855107,

Bihar, India.

E-mail: arupbanerjee1953@gmail.com

DOI: $10.14260 /$ jemds $/ 2017 / 699$

\section{(c) $(7)$}

customs of inhabitants.[2] Poverty, illiteracy, high population density, proximity with animals, poor hygiene conditions along with unavailability of safe and potable water attribute to the higher prevalence of intestinal parasites in developing nations. ${ }^{[3]}$ Moreover, certain environmental factors like pollution, global warming and tropical humid weather conditions facilitate disease. These factors have a direct bearing on the frequency of parasitic infections, and consequently the prevalence of infection varies in different states of India. ${ }^{[4]}$

The most common intestinal parasitic infestations as reported globally are Ascaris (20\%), hookworm (18\%), Trichuris trichiura (10\%) and Entamoeba histolytica (10\%).[5] The WHO estimates that approximately 50 million people worldwide suffer from invasive amoebic infections each year, resulting in 40000-100000 deaths annually.[6] Human beings acquire IPIs through several routes, including faecal-oral and skin penetration, and it causes untold suffering. Food-handlers may serve as the transmission agents and reservoirs of infection.[7] The main clinical 
manifestation of the disease caused by these parasites is diarrhoea. ${ }^{[2]}$ In India, the overall prevalence rate of IPI ranges from $12.5 \%$ to $66 \%$ with varying prevalence rates for individual parasite. ${ }^{[8]}$

Seasonal variations in temperature, rainfall and resource availability are ubiquitous and can exert strong pressures on population dynamics.[9] Some of the theories relating seasonality with host-parasite systems have found the incidence of many infectious diseases due to changes in susceptibility of the human host to the particular pathogen.[10] Several past studies, including a study on humans from the United States and a few others using animal subjects have revealed the burden of parasitic infections to rise during the monsoon months (July to October), showing the lowest load during winter.[11,12]

Many factors or combinations of factors contributing to disease emergence include ecological changes, such as those due to human activities or anomalies in climate; demographic changes and behavioural changes, travel and immigration, technology and industry; microbial adaptation, change and breakdown of public health measures. The emerging infectious diseases are also attributed to the population growth, ageing population, poverty and malnutrition, environmental pollution, deforestation, crowding, inadequate infrastructure, poor sanitation and water supply, global warming, development of antimicrobial/insecticide resistance, etc. In addition to this, the immunocompromised patients including patients with AIDS, solid organ transplant recipients, and patients on immunosuppressive therapy for disorders, are at high risk for opportunistic parasites.[13]

Bihar state is land-locked, bordered to the north by Nepal and split by the river Ganges which flows from west to east through the state. Located far from the sea and influenced by the Himalayas, the state has a continental monsoon climate, typical of most of the Northern India.[14] Studies of seasonal parasitic prevalence amongst large patient populations are rarely reported from Bihar, where endemic parasitosis is still high, due to poor hygiene practices and high population density. It is important to know the monthly and season-wise distribution of single and multiple parasitic infections, in order to determine the peak incidence period. Therefore, in an attempt to assess the influence of seasonal variations on the prevalence of IPI, a retrospective study was done for a period of 36 months in our Tertiary Care Hospital in the eastern part of Bihar.

\section{MATERIALS AND METHODS}

The present study is a retrospective study undertaken in a rural medical college and multispecialty hospital in eastern region of Bihar, India. Patients of all ages who reported to medical and paediatric OPDs of the hospital during the period of Jan. 2014 to Dec. 2016 with gastro-intestinal symptoms and who were subjected to routine stool examinations were included in the study. A total number of 5638 patients of both sexes were found to fulfil the criteria of inclusion. The age range of the patient population was 03 years to 76 years.

\section{Specimen Collection}

A single stool specimen was collected from each patient in a clean wide-mouthed container. Freshly voided stool specimens were processed using formol-ether concentration technique and examined microscopically for ova, cysts or parasites using saline and iodine mounts on grease free slides. Part of the stool specimen was preserved in $10 \%$ formal-saline and from this a concentrated smear was made on a grease-free slide, fixed with methanol and stained by a modified Ziehl-Neelsen stain. Routine macroscopic examinations were carried as per standard guidelines for consistency, colour, presence of mucus and blood and presence of adult worms, scolices and proglottids.

For microscopic examinations, saline wet mount and Lugol's iodine wet mount were prepared as per standard protocol. Each sample was examined under microscope for presence of ova, parasites and cysts.

The summer season was defined as the period between $16^{\text {th }}$ April and $15^{\text {th }}$ June; rainy season was defined as the period in between $16^{\text {th }}$ June and $15^{\text {th }}$ August. Similarly, autumn, dewy, winter and spring seasons were defined as the periods between $16^{\text {th }}$ August and $15^{\text {th }}$ October, $16^{\text {th }}$ October and $15^{\text {th }}$ December, $16^{\text {th }}$ December and $15^{\text {th }}$ February and $16^{\text {th }}$ February and $15^{\text {th }}$ April respectively.

\section{RESULTS}

The results are tabulated and depicted in Table 1 and Figure 1. Some of the stool specimens showed more than one parasite.

\begin{tabular}{|c|c|c|c|c|c|c|c|c|}
\hline Parasites & $\begin{array}{c}\text { Total } \\
\text { Specimen }\end{array}$ & $\begin{array}{c}\text { Parasite +ve } \\
\text { Specimen }\end{array}$ & $\begin{array}{c}\text { Ascaris } \\
\text { lumbricoides }\end{array}$ & $\begin{array}{c}\text { Entamoeba } \\
\text { histolytica }\end{array}$ & $\begin{array}{c}\text { Giardia } \\
\text { lamblia }\end{array}$ & $\begin{array}{c}\text { Ancylostoma } \\
\text { duodenale }\end{array}$ & $\begin{array}{c}\text { Enterobius } \\
\text { vermicularis }\end{array}$ & 0thers \\
\hline Summer & 1236 & 601 & 86 & 228 & 98 & 49 & 79 & 83 \\
\hline Rainy Season & 1489 & 698 & 115 & 238 & 112 & 56 & 74 & 130 \\
\hline Autumn & 912 & 417 & 54 & 138 & 82 & 58 & 46 & 58 \\
\hline Dewy Season & 783 & 389 & 36 & 122 & 165 & 36 & 26 & 22 \\
\hline Winter & 594 & 251 & 28 & 85 & 52 & 34 & 35 & 28 \\
\hline Spring & 624 & 316 & 38 & 101 & 54 & 41 & 62 & 37 \\
\hline Total & 5638 & 2672 & 357 & 912 & 563 & 274 & 322 & 358 \\
\hline \multicolumn{7}{|c|}{ Table 1. Intestinal Parasites found in Different Seasons } \\
\hline
\end{tabular}




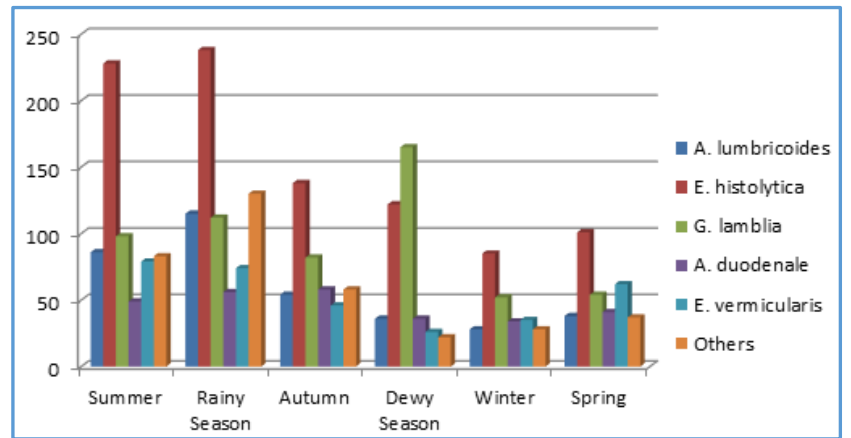

Figure 1. Season-wise distribution of Different Intestinal Parasites

\section{DISCUSSION}

In total, our study was done retrospectively on 5638 stool specimens obtained from patients who were suspected to have intestinal parasitosis and were referred from outpatient departments (OPD). The samples were examined first under naked eye for consistency, colour, appearance, etc. and then under microscope for the detection of any ova, parasites and cysts of any of the intestinal parasites. The study period was for three years.

It was found in our study that out of 5638 stool specimens examined, 1489 were sent during the monsoon itself out of which 698 (46.88\%) specimens were positive for parasites. In other words, out of total 2672 parasite-positive specimens in a total span of three years, the monsoon brunt was $26.12 \%$, compared to the winter counterpart which was 251 , i.e. only $9.39 \%$. After rainy season, the next parasitic cases were found in the order of: summer (601, i.e. $22.47 \%)$, autumn (417, i.e. $15.6 \%)$, dewy season (389, i.e. $14.56 \%)$, spring (316, i.e. $11.83 \%$ ) and lastly winter as already mentioned (251, i.e. $9.39 \%)$. It has to be noted here that rainfall does not necessarily occur solely during rainy season, but also in other seasons, notably in summer and autumn. However, the rainfall is least during dewy season and winter, the latter being usually practically rain-free.

In the monsoon, the commonest intestinal parasite observed is Entamoeba histolytica which is also the commonest in all other seasons. But, after that, in other seasons the next common parasites are Ascaris lumbricoides and Giardia lamblia. Most interestingly in monsoon, the commonest parasites are the so-called less common parasites, grouped as "others" in our study. These parasites include: Hymenolepis nana, Taenia solium/saginata, Trichuris trichiura and Strongyloides stercoralis. Enterobius vermicularis, notably again is more common in summer (79 in the total three-year study), compared to 74 in the rainy season in these three years. Ancylostoma duodenale (56) occupies the next in order in the rainy season. In spring also, though the number of parasite-positive cases were less than half (316) compared to monsoon, the cases of E. vermicularis were quite significant (62).

For many years, gastrointestinal parasites in animals and livestock are monitored by studying the number of eggs from faecal samples of animals over all different seasons of the year.[15] On the other hand, meteorological data and computer simulation are at present deemed as an alternative approach for forecasting gastrointestinal parasitic infestation in many developed countries.[16, 17] Altitudes of the places, temperature, humidity and rainfall are factors responsible for both temporal (i.e. seasonal) and spatial variation of intestinal parasites.

A study from Meghalaya, India shows that the most common gastrointestinal parasite prevalent throughout the year is Strongyloides stercoralis.[18] The reasons for that could be the high rainfall and humidity prevalent in the north-eastern regions of India, which augments the freeliving larval development in soil to complete the life-cycle of strongyle group of parasites.[19]

Prevalence of gastrointestinal parasitic load in animals measured by egg per gram of faeces (EPG) was found to have a linear correlation both with rainfall in millimetre and temperature $\left({ }^{\circ} \mathrm{C}\right)$ of the region. ${ }^{[20]}$ It was also noted that beyond a critical temperature (around $30^{\circ} \mathrm{C}$ ) the EPG rises enormously. Rainfall directly influences the pathogenicity of the parasitic infection level. Unlike other bacterial and viral infections, the gastrointestinal parasites maintain a steady host sustainable relationship, which prevents the host from dying out of this infection. Simultaneously, the parasite contributes to a severe loss of production level in animals through nutrition sharing with the host. Therefore, to prevent production loss, it was suggested by those authors that parasite-controlling anti-helminthic therapy (both preventive and curative) should be implemented at the time in the region when the rainfall is above $100 \mathrm{~mm}$ and the ambient temperature is around $30^{\circ} \mathrm{C}$.

Seasonal variations of gastrointestinal parasitosis have also been reported by some other investigators.[21,22] Intestinal parasitic infection is significantly associated with rainy season among HIV patients. Furthermore, rainy season may facilitate conditions and risk factors predisposing to intestinal parasitic infections. Indeed, other parasitic infections such as malaria parasitaemia have been reported to have higher prevalence in the rainy season. Considering individual parasitic agents, Cryptosporidium species and Strongyloides stercoralis were the only parasitic agents that were associated with rainy season. The finding of Cryptosporidium in association with rainy season had been noted and its transmission is via different routes such as water, person-to person, contact with animal, etc. During the rainy season cattle are seen roaming and grazing freely and as a result defecate on soil. These faeces are washed into nearby streams, and rivers by flood of rain.[21] For parasites where eggs are deposited in faeces, temperature can influence both rates of parasite development and the survival of external stages. For larval stages to develop, first the temperature must exceed a critical threshold, and then parasite development rates further increase with temperature above this threshold. Moisture is also critical for the development, survival and movements of helminth larvae. Dry conditions can limit transmission and cause larvae to migrate into the soil, although excessive rainfall can wash away eggs and other infectious stages. ${ }^{[9]}$ Consumption of such contaminated water can lead to Cryptosporidial infection and indeed, the prevalence of Cryptosporidial infection has been reported to be higher among HIV patients that use streams and rivers as a source of water.

In resource-poor settings, mostly people walk and play in open field barefooted, especially in the rainy season and these habits increase the chances of Strongyloides stercoralis infection. This may explain the association of S. stercoralis with the rainy season. Although, a similar mechanism of 
infection is also utilised by hookworm, the reason for the lack of association between hookworm and season is unclear. No significant association was seen between intestinal parasitic infection and seasonal variation among the non-HIV patients and the reason for this finding is unclear. Ascaris lumbricoides and hookworm infections were the only intestinal parasites recovered from the non- HIV patients.[21] However, our study is probably the first of its kind originally from Bihar which emphasises on the relationship of seasonal changes with that of intestinal parasitosis.

\section{CONCLUSION}

From our as well as other national and international studies, it can now be safely concluded that seasonal variations do occur in the rates of occurrences of different intestinal parasite infestations, due to differences in temperature, humidity and rainfall, in particular. These findings could be utilised for proper timing of preventive anti-helminthic therapy as is done in school children and also for more detailed analysis and further research.

\section{REFERENCES}

[1] Kotian S, Sharma M, Juyal D, et al. Intestinal parasitic infection-intensity, prevalence and associated risk factors, a study in the general population from the Uttarakhand hills. Int J Med Public Health 2014;4(4):422-5.

[2] Pawar S, Ingole K, Bhise M. Study of prevalence of intestinal parasitic infection in symptomatic children at tertiary care hospital. Int J App Res 2016;2(4):2438.

[3] Padmaja N, Swaroop SP, Nageswararao P. Prevalence of intestinal parasitic infections among school children in and around Amalapuram. J Pub Health Med Res 2014;2(2):36-8.

[4] Singh BB, Sharma R, Sharma JK, et al. Parasitic Zoonoses in India: an overview. Rev Sci Tech 2010;29(3):629-37.

[5] Ahir HR, Patel PH, Nerurkar AB. Intestinal parasitic infections in patients attending tertiary care hospital, Valsad, south Gujarat, India: a retrospective study. J Pharm Biomed Sci 2015;05(02):117-121.

[6] Haque R. Human intestinal parasites. J Health Popul Nutr 2007;25(4):387-91.

[7] Kamau P, Aloo-Obudho P, Kabiru E, et al. Prevalence of intestinal parasitic infections in certified foodhandlers working in food establishments in the city of Nairobi, Kenya. J Biomed Res 2012;26(2):84-9.

[8] Khan T, Jamali S, Kumar A. Prevalence of common intestinal parasites in patients attending tertiary care hospital, Lucknow, India. J Biol Chem Res 2016;33(1):586-97.
[9] Altizer S, Dobson A, Hosseini P, et al. Seasonality and the dynamics of infectious diseases. Ecol Lett 2006;9(4):467-84.

[10] Dowell SF. Seasonal variation in host susceptibility and cycles of certain infectious diseases. Emerg Infect Dis 2001;7(3):369-73.

[11] Amin OM. Seasonal prevalence of intestinal parasites in the United States during 2000. Am J Trop Med Hyg 2002;66(6):799-803.

[12] Singh AK, Gupta MK. Study on prevalence of intestinal parasitic infections among school children. Global J Res Anal 2016;5(9):53-4.

[13] Prasad KJ. Emerging and re-emerging parasitic diseases. J Int Med Sci Acad 2010;23(1):45-50.

[14] Greenland K, Dixon R, Khan SA, et al. The epidemiology of soil-transmitted helminths in Bihar State, India. PLoS Negl Trop Dis 2015;9(5):e0003790.

[15] Mandal S, Bandyopadhyay S, Datta KK, et al. Economic analysis of risk of gastrointestinal parasitic infection in cattle in north eastern states of India. Trop Anim Heal Prod 2010;42(7):1481-6.

[16] Mackay CR, Maddox JF, Brandon MR. Lymphocyte antigens of sheep: identification and characterization using a panel of monoclonal antibodies. Vet Immunol Immunopathol 1987;17(1-4):91-102.

[17] Turnbull IF, Bowles VM, Wiltshire CJ, et al. Systemic immunization of sheep with surface antigens from Haemonchus contortus larvae. Int J Parasitol 1992;22(4):537-40.

[18] Bandyopadhyay S, Devi P, Naskar S, et al. Incidence of strongyle infection in cattle and pig with relevance to rainfall in Meghalaya. Webmedcentral 2010;1(10):WMC00889.

[19] Soulsby EJL. Helminths, arthropods and protozoa of domesticated animals. $7^{\text {th }}$ edn. London: Bailliere Tindall 1982.

[20] Chattopadhyay AK, Bandyopadhyay S. Seasonal variations of EPG levels in gastro-intestinal parasitic infection in a Southeast Asian controlled locale: a statistical analysis. Springer Plus 2013;2:205.

[21] Akinbo FO, Okaka CE, Omoregie R. Seasonal variation of intestinal parasitic infections among HIV positive patient in Benin city, Nigeria. Ethiopian J Health Sci 2011;21(3):191-4.

[22] Raharivololona BM, Ganzhorn JU. Seasonal variations in gastrointestinal parasites excreted by the grey mouse lemur Microcebus murinus in Madagascar. Endaz Species Res 2010;11:113-122. 